\title{
Epidemiology of cardiac arrest outside and inside hospital Experiences from registries in Sweden
}

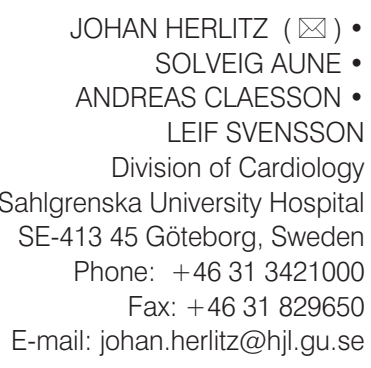

\author{
JOHAN HERLITZ • SOLVEIG AUNE - ANDREAS CLAESSON • \\ LEIF SVENSSON
}

\begin{abstract}
Cardiac arrest is a dramatic condition leading to sudden death if someone cannot perform two interventions, basic life support and early defibrillation, that have been proved to improve long-term survival. The 'Utstein style', recently introduced, represents a standard of practice both inside and outside hospital with recommended guidelines for the uniform reporting of clinical data from the patient suffering cardiac arrest. In Sweden the vast majority of patients suffering from cardiac arrest regardless whether inside or outside hospital are included in webbased national registers (one for out-of-hospital cardiac arrest (OHCA) and one for in-hospital-cardiac arrest (IHCA)). In this article we will present our experiences from OHCA and IHCA separately.
\end{abstract}

Keywords: cardiac arrest outside and inside hospital, epidemiology, The Swedish register, survival, cerebral function

\section{Introduction}

A cardiac arrest is, when unexpected, always a dramatic event where the chance of survival is dependent on whether treatment is optimal during the first minutes after the event.

By tradition we use to divide the cardiac arrest into two groups:

a/ Out of hospital cardiac arrest (OHCA) and

b/ In hospital cardiac arrest (IHCA).

This division can be regarded as an artificial division since the pathophysiology is often the same (at least when there is a cardiac etiology)

However, some etiologies such as drowning and traumatic cardiac arrest will in principle only take place outside the hospital. In this article we will present our experiences from OHCA and IHCA separately.

\section{Out of hospital cardiac arrest \\ Background}

Register work started already in the beginning of the 80:ties in Göteborg (500.000 inhabitants). With the introduction of automated external defibrillators (AED:s) in the first tier in a two-tier system a survival to hospital discharge rate of $13 \%$ (30\% among patients found in ventricular fibrillation (VF)) was reported (1) However, a relatively high proportion of survivors had a cerebral performance categories (CPC) score of more than 2. These results were achieved with a short delay from a cardiac arrest to defibrillation (median of 5 minutes) and a relatively low rate of bystander cardiopulmonary resuscitation (CPR) (20\%). Such a high survival has not been reported thereafter in Göteborg.

\section{The Swedish Register The start}

Our national register was started in 1990 and has thereafter successively been built up. It was a paperbased register until 2007. Since then a webbased register was started and today all ambulance organisations join the web.

\section{Representativeness}

Today all ambulance organisations in Sweden join the registry. Based on validations of part of the register we estimate that we cover about $80 \%$ of $\mathrm{OHCA}$ in Sweden where resuscitation was attempted. We thus estimate that there are 4.000 such cases in Sweden (9 million inhabitants; between 40 and 50 per 100.000 inhabitants and year). Last year (2009) 3.290 cases were reported to the register.

Survival. Up to the beginning of this century survival to 1 month varied between $4 \%$ and $5 \%$. During the last years we have seen an increase up to nearly $8 \%$. (2)

This mean that we calculate to rescue about 300 persons each year in Sweden after OHCA. The increase in survival has been seen only among 
patients found in a shockable rhythm, where today survival to 1 month is just above $20 \%$. Among patients found in a non shockable rhythm survival to one month has remained surprisingly low (between 1\% and 2\%).

Cerebral function. In the webbased register we estimate cerebral function at hospital discharge among survivors according to CPC-score. Preliminary data indicate that more than $90 \%$ have an acceptable cerebral function (CPCscore of 1 and 2). The majority of these cases have a CPC-score of 1. According to experiences from Göteborg CPC score among survivors after OHCA have improved over years. (3)

Bystander CPR. Since the beginning of the 90:ties there have been a successive increase in bystander CPR from about $30 \%$ to just above $60 \%$ in 2009 . This is explained by the mass education in CPR that has taken place over years in the community in Sweden. (4) The increase in bystander CPR has been found to be a contributing factor to the increase in survival after OHCA in the country. (2) The proportion of the bystander CPR performed by lay persons has increased from 65\% in 1992 to $77 \%$ in 2009.

Ventricular fibrillation. Since the beginning of the 90:ths there has been a moderate decrease in the proportion of patients found in VF from 34\% in 1992 to $25 \%$ in 2009 . However, the decrease was found in the 90ties and the proportion of patients found in a shockable rhythm has remained stable during the last 10 years.

Delay time. The median ambulance response time (from call for ambulance until arrival on scene) has increased from 6 minutes in the beginning of the 90ths to 9 minutes in 2009. Similarly has the median delay from call for ambulance to defibrillation increased from 8 minutes in the beginning of the 90ths to 11 minutes in 2009.

Witnessed status. The proportion of OHCA cases witnessed by the crew has increased from 10\% in 1992 to $17 \%$ in 2009 . The increase in crew witnessed cases indicate that patients today call earlier if symptoms which increases the risk for a cardiac arrest such as chest pain or dyspnoea. The increase in crew witnessed cases has been reported to be a contributing factor to the increase in survival after $\mathrm{OHCA}$ in Sweden. (2)

\section{In hospital cardiac arrest Background}

A register for IHCA started in Göteborg in 1994 in Sahlgrenska University Hospital. The catchment population for the hospital is 250.000 inhabitants. We found a surprisingly high survival to hospital discharge rate of about $35 \%$. $(5,6)$ One contributing factor to this finding was most likely the high frequency of "do not attempt resuscitation" (DNAR). It was found that CPR started in only $11 \%$ of all patients suffering from IHCA. (7)

\section{The Swedish Register}

The start. The Swedish Register for IHCA was webbased already from the beginning. Hospitals started to use the web in 2005. Today 54 out of 72 hospitals in the country $(75 \%)$ have joined the register and about 6.000 cases with IHCA in which CPR was started are included.

Results. Data so far are preliminary since a number of the participating hospitals have reported to the register for a relatively short time. The rate of survival to hospital discharge is about $30 \%$ (about 60\% for patients found in a shockable rhythm and about $20 \%$ for patients found in a non shockable rhythm.

Among survivors more than $90 \%$ have a CPC-score of 1 or 2 indicating an acceptable cerebral function.

\section{Overall conclusion}

In Sweden the vast majority of patients suffering from cardiac arrest regardless whether inside or outside hospital are included in webbased national registers (one for OHCA and one for IHCA). Survival of IHCA is about 4 times as high as after OHCA. We estimate that more than 1.000 patients are successfully resuscitated after cardiac arrest in Sweden each year. The majority of survivors are recruited from IHCA. Regardless of localisation of the cardiac arrest the majority of survivors have an acceptable cerebral function.

\section{REFERENCES}

1. Ekström L, Herlitz J, Wennerblom B, Axelsson Å, Bång A, Holmberg S.

Survival after cardiac arrest outside hospital over a 12-year period in Göteborg. Resuscitation 1994;27:181-7.

2. Hollenberg J, Herlitz J, Lindqvist J, Riva G, Bohm K, Rosenqvist M, et al. Improved survival after out-of-hospital cardiac arrest is associated with an increase in proportion of emergency crew - witnessed cases and bystander cardiopulmonary resuscitation Circulation 2008;118:389-96.

3. Martinell L, Larsson M, Bång A, Lindqvist J, Thorén A-B, Herlitz J. Survival in out of hospital cardiac arrest before and after use of advanced post resuscitation care. A survey focusing on incidence patient characteristics, survival and estimated cerebral function after postresuscitation care. Am J Emerg Med 2010;28:543-51.

4. Strömsöe A, Andersson B, Ekström L, Herlitz J, Axelsson A, Göransson KE, et al. Education in cardiopulmonary resuscitation in Sweden and its clinical consequences. Resuscitation 2010;81:211-6.

5. Andréasson A-Ch, Herlitz J, Bång A, Ekström L, Lindqvist J, Lundström G, et al. Characteristics and outcome among patients with a suspected in hospital cardiac arrest. Resuscitation 1998;39: 23-31.

6. Fredriksson M, Aune S, Bång A, Thorén A-B, Lindqvist J, Karlsson T, et al. Cardiac arrest outside and inside hospital in a community. Mechanisms behind the differences in outcome and outcome in relation to time of arrest. Am Heart J 2010;159:749-56.

7. Aune S, Herlitz J, Bång A. Characteristics of patients who die in hospital with no attempt at resuscitation. Resuscitation 2005;65:291-9. 